\title{
Models of Traumatic Cerebellar Injury
}

\author{
Matthew B. Potts • Hita Adwanikar • \\ Linda J. Noble-Haeusslein
}

Published online: 5 June 2009

(C) The Author(s) 2009. This article is published with open access at Springerlink.com

\begin{abstract}
Traumatic brain injury (TBI) is a major cause of morbidity and mortality worldwide. Studies of human TBI demonstrate that the cerebellum is sometimes affected even when the initial mechanical insult is directed to the cerebral cortex. Some of the components of TBI, including ataxia, postural instability, tremor, impairments in balance and fine motor skills, and even cognitive deficits, may be attributed in part to cerebellar damage. Animal models of TBI have begun to explore the vulnerability of the cerebellum. In this paper, we review the clinical presentation, pathogenesis, and putative mechanisms underlying cerebellar damage with an emphasis on experimental models that have been used to further elucidate this poorly understood but important aspect of TBI. Animal models of indirect (supratentorial) trauma to the cerebellum, including fluid percussion, controlled cortical impact, weight drop impact acceleration, and rotational acceleration injuries, are considered. In addition, we describe models that produce direct trauma to the cerebellum as well as those that reproduce specific components of TBI including axotomy, stab injury, in vitro stretch injury, and excitotoxicity. Overall, these models reveal robust characteristics of cerebellar damage including regionally specific Purkinje cell injury or loss,
\end{abstract}

Matthew B. Potts and Hita Adwanikar shared first-authorship.

M. B. Potts $\cdot$ H. Adwanikar

Brain and Spinal Injury Center,

Department of Neurological Surgery, University of California,

San Francisco, CA 94143, USA

L. J. Noble-Haeusslein $(\square)$

Brain and Spinal Injury Center, Departments of Neurological

Surgery and Physical Therapy and Rehabilitation Science,

University of California,

521 Parnassus Ave, Room C-224, Box 0520,

San Francisco, CA 94143, USA

e-mail: linda.noble@ucsf.edu activation of glia in a distinct spatial pattern, and traumatic axonal injury. Further research is needed to better understand the mechanisms underlying the pathogenesis of cerebellar trauma, and the experimental models discussed here offer an important first step toward achieving that objective.

Keywords Cerebellum - Traumatic brain injury . Animal model

\section{Introduction}

Traumatic brain injury (TBI) is a major cause of morbidity and mortality worldwide, affecting up to ten million people annually [1]. Approximately $2 \%$ of the population in the USA alone shows a long-term disability as a result of TBI [2], including cognitive, psychological, motor, and sensory deficits. Some of the neurologic findings following TBI may be attributed to cerebellar damage, including ataxia, postural instability, tremor, impairments in balance and fine motor skills, and possibly even cognitive deficits [3-8]. Direct cerebellar injury is much less common than supratentorial trauma [9], and radiologic studies of TBI confirm that the cerebellum is often affected even when the initial injury does not directly involve this structure $[10,11]$. It is therefore important to gain an understanding of the factors leading to such cerebellar damage. This review characterizes the current literature on the cerebellar component of TBI with an emphasis on the experimental models that are being used to further understand this important but poorly studied aspect of TBI.

\section{Human TBI and Cerebellar Deficits}

The Brain-Injured Adult A few studies have specifically addressed the effects of human TBI on the cerebellum, 
including both direct and indirect cerebellar injury. One such study showed that only $3.3 \%$ of brain-injured adult patients had primary posterior fossa lesions, with $25 \%$ of those lesions involving the cerebellum [9], suggesting that direct cerebellar injury is a relatively uncommon phenomenon. Some of the classically described consequences of direct traumatic injury to the cerebellum are hypotonia, ataxia, dysmetria, tremor, dysdiadochokinesis, and vertigo [12]. Cerebellar mutism, characterized by impairment in verbal communication from cerebellar injury, has also been described [13]. Syndromes of delayed-onset cerebellar symptoms also develop in a subset of TBI patients within 3 weeks to 2 years after injury and include the aforementioned symptoms as well as nystagmus and dysarthria [6, 14]. Interestingly, these studies of delayed-onset cerebellar syndromes actually described patients with lesions in the thalamus or brainstem [6, 14], suggesting that such TBIinduced symptoms may be due to pathways involving the cerebellum, such as the dentate-rubro-olivary pathway, rather than purely direct cerebellar trauma [14]. The cerebellum exhibits pathological changes including selective cell loss, altered metabolism, and white matter injury after focal and diffuse TBI. There are several clinical reports of cerebellar atrophy following TBI [15, 16]. Metabolic changes have also been documented in the cerebellum both ipsilaterally and contralaterally to the cortical injury [17-19]. Hypermetabolism within the cerebellar vermis compared to the cerebellar hemispheres has been shown in studies investigating cerebellar metabolism after TBI [20]. The metabolic rate of glucose is depressed within the cerebellum in comatose patients compared to non-comatose brain-injured patients [21]. In addition, loss of cerebellar gray matter after TBI has been documented [16].

Clinical observations implicate the cerebellum in cognitive function. Impairments in learning tasks and planning as well as a lack of awareness of incorrect responses have been correlated with cerebellar damage [22, 23]. These findings, which suggest a functional link between the cerebellum and higher order cognitive function, are supported by anatomical evidence of projections from the cerebellum to an area of the prefrontal cortex known to be involved in spatial memory [24]. Thus, behavioral deficits commonly observed in brain-injured patients may have a basis in the vulnerability of the cerebellum.

The Brain-Injured Child Although TBI-induced cerebellar damage has been primarily studied in the adult, cerebellar damage may likewise be evident in the brain-injured child. Braga et al. [3] investigated brain magnetic resonance (MRI) findings and neuropsychological sequelae in a series of children who suffered severe TBI and showed an association between cerebellar lesions and deficits in visual recognition memory, arithmetic, object assembly, and overall intelligence quotient. Cerebellar mutism has also been reported in children with cerebellar trauma [13, 25]. Similar to the adult, indirect supratentorial trauma can lead to cerebellar damage in the brain-injured child. Spanos et al. [10] examined MRI images in children an average of 3.1 years after severe TBI and found significant cerebellar white and gray matter loss when compared to age-matched uninjured children (Fig. 1). This difference held true with white matter loss even when children with focal cerebellar lesions were excluded. These investigators examined other brain structures with known connections to the cerebellum such as the thalamus, pons, and dorsolateral frontal cortex. In uninjured children, there was a significant positive correlation between the volumes of white matter in the cerebellum and each of these regions. In injured children, however, such a relationship was lost between the cerebellum, thalamus, and dorsolateral frontal cortex. These findings suggest that cerebellar white matter loss may not be entirely due to retrograde axonal degeneration from other damaged structures but that other mechanisms may be involved. Sato-Ares et al. [11] similarly studied cerebellar findings in brain-injured children an average of 16 months after moderate to severe TBI and demonstrated cerebellar atrophy in patients whose initial injury was to the frontal and temporal regions. In these children, injury-induced cerebellar atrophy was correlated with poor performance on standard intelligence quotient tests.

Matschke et al. [26] have also demonstrated the neuropathologic consequences of TBI in a unique case report of a 4-year-old girl who had suffered mild TBI with an occipital skull fracture and expired 3 weeks later due to unrelated causes. At autopsy, they noted significant cerebellar atrophy with loss of Purkinje cells and activation of microglia. These findings correlate the cerebellar atrophy seen in radiologic studies with vulnerability of Purkinje cells to TBI.

Summary of Clinical Findings Overall, these clinical studies show that the cerebellum is often affected in TBI, both directly and indirectly. However, the causes of indirect cerebellar damage resulting from supratentorial trauma are not completely understood. Moreover, given the complexity of human TBI, the long-term consequences of such cerebellar damage have yet to be completely elucidated. It is also unknown if age at the time of injury is a determinant of cerebellar vulnerability and influences pathogenesis and long-term behavioral outcomes.

Experimental models have and will continue to play an important role in furthering our understanding of traumatic injury to the cerebellum. We will now discuss the current models of traumatic cerebellar injury with respect to their technical aspects, the findings they have provided, and how those findings translate to the human condition. 
Fig. 1. Comparison of cerebellar images from a 16-year-old boy after TBI $(\mathbf{a}, \mathbf{b}, \mathbf{c})$ and an age-matched uninjured patient (d, e, f). a, d T1-weighted sagittal magnetic resonance image (MRI); b, e T2-weighted axial MRI; c, f T1-weighted coronal MRI. Cerebellar atrophy can be clearly seen in the injured brain. Reproduced with permission from Spanos et al. [10]
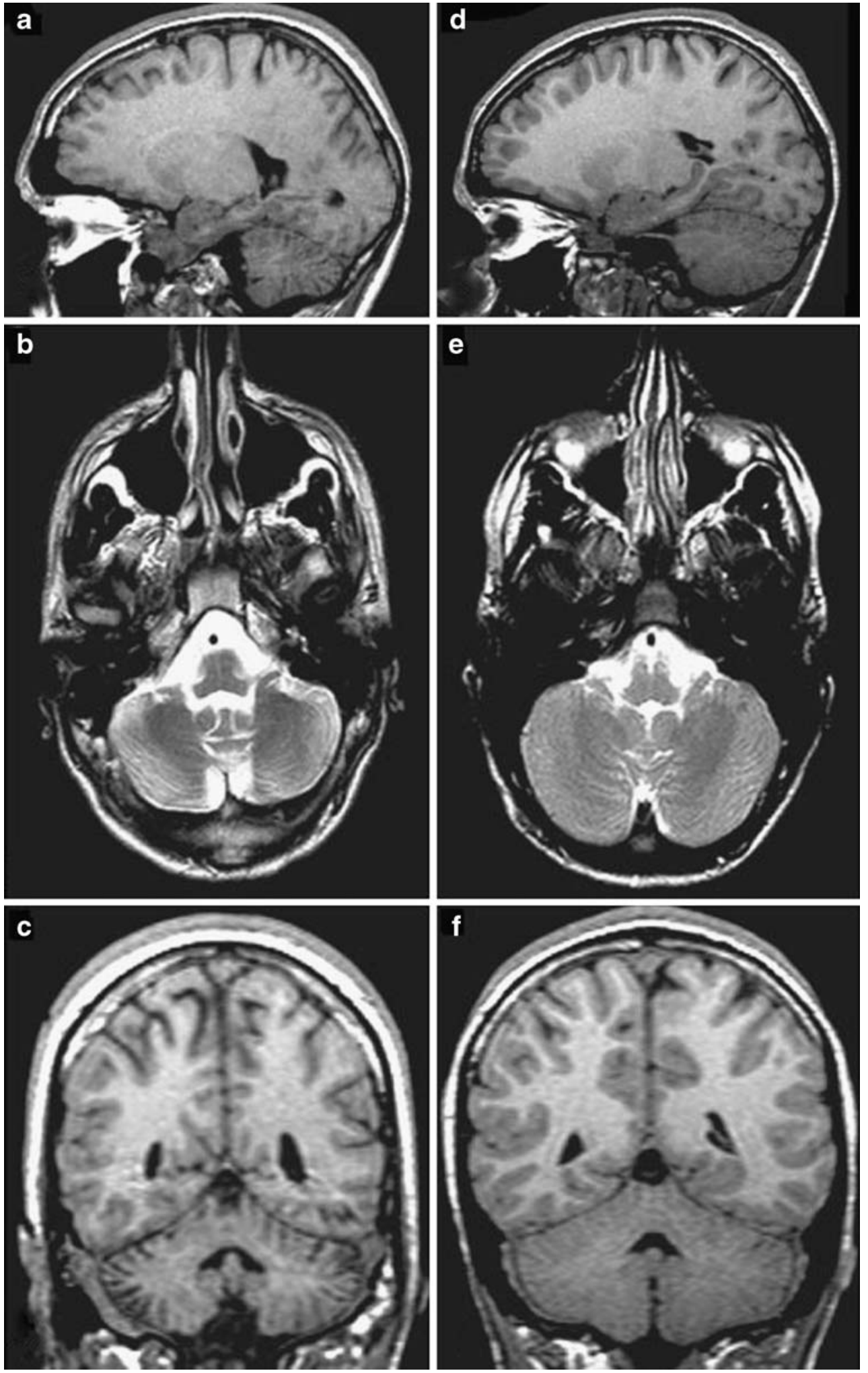

Models of TBI Leading to Indirect Cerebellar Damage

Human TBI is characterized by a complex pathophysiology due to the fact that it encompasses a wide range of possible injury mechanisms and locations. Here, we consider four experimental models of TBI, each of which has examined the cerebellum after traumatic injury to the cerebral cortex. These include fluid percussion injury, controlled cortical impact injury, weight drop impact acceleration injury, and rotational acceleration injury. 


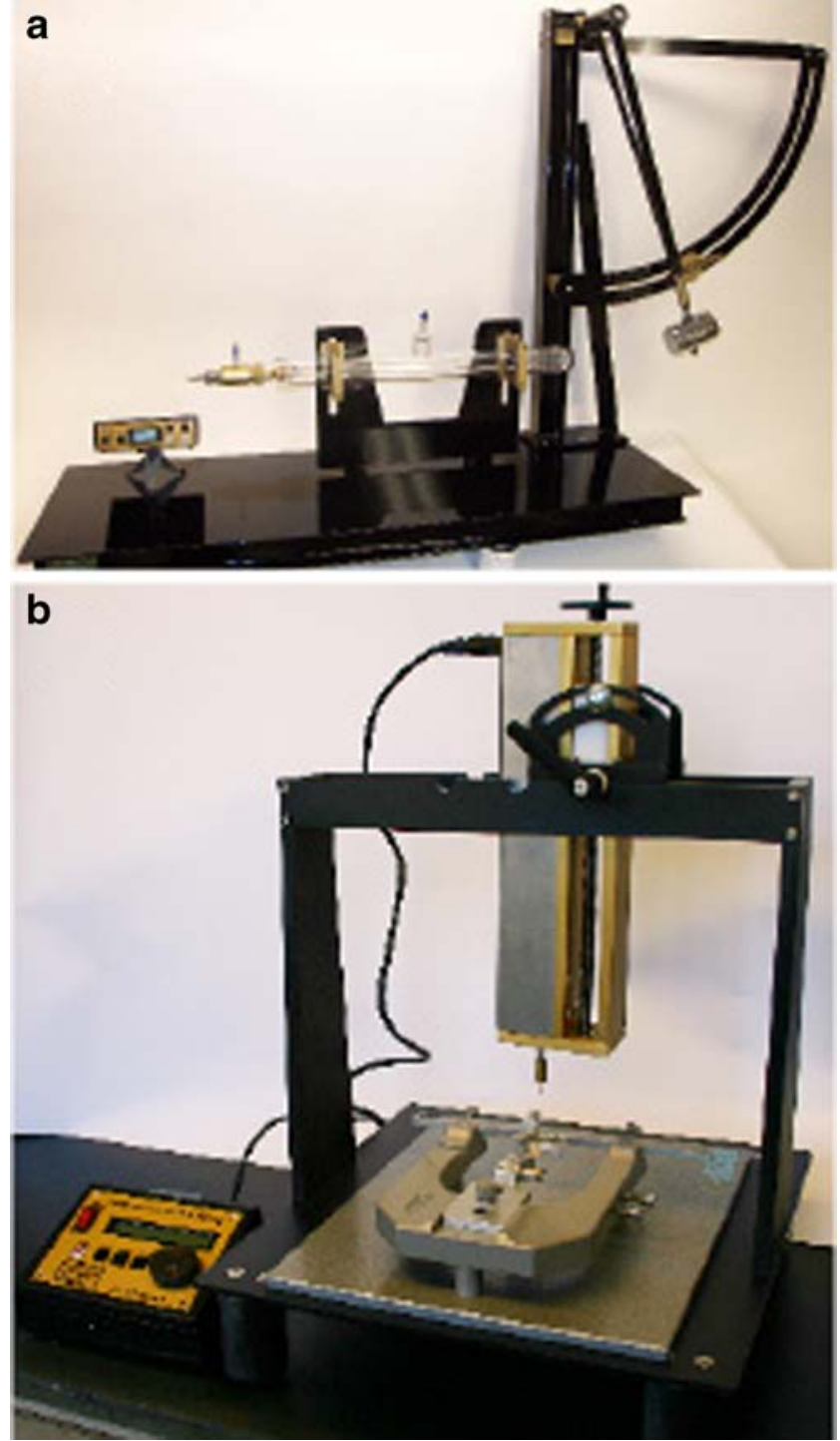

Fig. 2. Fluid percussion injury $(F P I)$ and controlled cortical impact $(C C I)$ injury are two of the most commonly used models in the study of traumatic cerebellar injury. a FPI is generated when a pendulum strikes a fluid-filled piston that transmits a fluid pulse to the surface of the brain. b CCI injury is generated when an electronically controlled piston strikes the surface of the brain. a Photograph provided by Guy Blankenship, Custom Design and Fabrication, Department of Radiology, Virginia Commonwealth University Medical Center

Fluid Percussion Injury This model of brain trauma generates both focal and diffuse injury, including a focal cerebral contusion and subarachnoid hemorrhage at the site of impact as well as more diffuse neuronal loss within the ipsilateral hippocampus, thalamus, striatum, amygdala, and medial septum [27]. To generate a fluid percussion injury (FPI), a fluid-filled reservoir is cemented to the skull overlying a region of exposed brain. A pendulum then strikes the reservoir to deliver a fluid pulse to the brain [27]. The severity of the injury is determined by the height from which the pendulum is dropped (Fig. 2a). Variations of this model include midline and lateral (parasagittal) impact sites, and it has been described in several species, including mice, rats, cats, and rabbits [27].

A distinct pattern of cerebellar damage has been observed following FPI. Fukuda et al. [28] evaluated a lateral fluid percussion-induced injury to the frontoparietal cortex and found Purkinje cell loss within the cerebellar vermis beginning 1 day post-injury and continuing through 7 days post-injury (Fig. 3). This finding was associated with microglial activation seen in a distinct pattern characterized by "stripes" of microglia extending from the Purkinje cell layer outward to the cerebellar cortex. This study found no evidence of early neuronal activation using c-Fos in both the cerebellum and the inferior olivary nucleus, which is the principle source of synaptic input to Purkinje cells. Such a finding suggests that Purkinje cell death may not be mediated through activation of climbing fibers from the inferior olive. Further studies revealed activation of the stress protein heme oxygenase-1 within Bergmann glia in a similar "striped" distribution within the cerebellar vermis [29] as well as evidence of Purkinje cell degeneration through 14 days post-injury [15]. Heme oxygenase-1 expression in the cerebellum mirrored the pattern of Purkinje cell loss, suggesting an association. A similar pattern of Purkinje cell loss and associated gliosis was found with a medial FPI, but such cell loss was most significant in the posterior cerebellar vermis compared to the middle and anterior regions of the vermis [30]. This could reflect an injury that is both less severe and located more medially than previous studies. Purkinje cell loss was also found to be dose-dependent in the context of injury severity [30]. Cells consistent with the morphology of Purkinje neurons in the cerebellum have been shown after FPI with Fluoro-Jade staining, which delineates degenerating neurons and their processes [15, 30, 31]. Behaviorally, significant motor deficits on the beam walk and inclined plane and memory deficits in the radial arm maze and Morris water maze have also been observed [31].

A midline cortical FPI shows a similar pattern of cerebellar damage. Mautes et al. [32] reported Purkinje cell degeneration in the cerebellar vermis. Reactive microglia were localized to the dendritic arborization of degenerating Purkinje cells by 7 days post-injury. In addition, widespread axonal degeneration has been demonstrated after FPI, including within the cerebellar vermis [33, 34]. These white matter changes are associated with deficits in motor tasks, suggesting that TBI-induced motor deficits may be in part related to cerebellar damage [33].

The role of subarachnoid hemorrhage in the pathogenesis of TBI-induced cerebellar injury was also examined using the FPI model. Endothelin-1 is a potent vasoconstrictor found in cerebrospinal fluid after TBI [35] and is thought to play a role in subarachnoid hemorrhage-induced 
damage after TBI. Administration of an endothelin-1 receptor antagonist (Ro 61-1790) resulted in reduced microglial activation in the cerebellum of the drug-treated group at 3 days post-injury [36]. This change, however, was not evident by 7 days post-injury and did not improve Purkinje cell survival, suggesting that the pathogenesis of TBI-induced Purkinje cell death is not limited to the acute post-injury period.

Controlled Cortical Impact Similar to FPI, controlledcortical impact $(\mathrm{CCI})$ produces a contusion at the site of impact and neuronal loss in such distant sites as the hippocampus, thalamus, and striatum. In general, however, CCI injuries are more focal than FPI, with the contusion being a larger component [37]. CCI injury is generated by striking a piston against the exposed surface of the brain [38, 39]. Changing either the velocity of the piston or the depth to which the brain is compressed typically modulates the severity of injury (Fig. 2b).

Interestingly, the pathology of injury in the cerebellum after CCI is similar to that resulting from FPI, including Purkinje cell loss and microglial activation within the cerebellar vermis [40]. As with FPI, pathogenesis is severity-dependent (Fig. 3). The similarities between FPI and CCI indicate that the sensitivity of the cerebellar vermis is a robust finding and not dependent upon a particular injury model.

Although studies of the cerebellum in the context of CCI have been primarily conducted in the adult brain, a few have considered the developing brain. When performed in mice at post-natal day 21 , this model reproduces many of the consequences of TBI that have been reported in children, such as focal contusions, subdural hematomas, and diffuse axonal injury [41]. Axonal degeneration within the cerebellar peduncles has been described as early as 3 days post-injury [41], giving further evidence that cerebellar sensitivity is a robust finding that extends across injury models, species, and ages.

Weight Drop Impact Acceleration Injury Compared to the FPI and CCI models, the weight drop impact acceleration injury (WDIA) model aims to generate a more diffuse TBI by delivering a force to the intact skull as opposed to the exposed brain [42, 43]. A rotational component to the injury is produced when the head, positioned against a soft pad, is displaced upon impact. Altering the height from
Fig. 3. Cerebellar sensitivity is a robust finding that is dependent on injury severity and extends across injury models. Both Purkinje cell injury (a, Fluoro-Jade staining) and microglial activation (b, OX-42 staining) have been demonstrated in models of trauma such as FPI (a) and CCI (b) as well as other models of cerebellar injury, including excitotoxic injury. The magnitudes of both Purkinje cell loss (c) and microglial activation (d) have been shown to be dependent upon injury severity, as demonstrated in the CCI model. a Degenerating Purkinje cell body (black arrow) and associated process (white arrow); adapted with permission from Sato et al. [15]. b-d Adapted with permission from Igarashi et al. [40]. Scale bars $50 \mu \mathrm{m}$
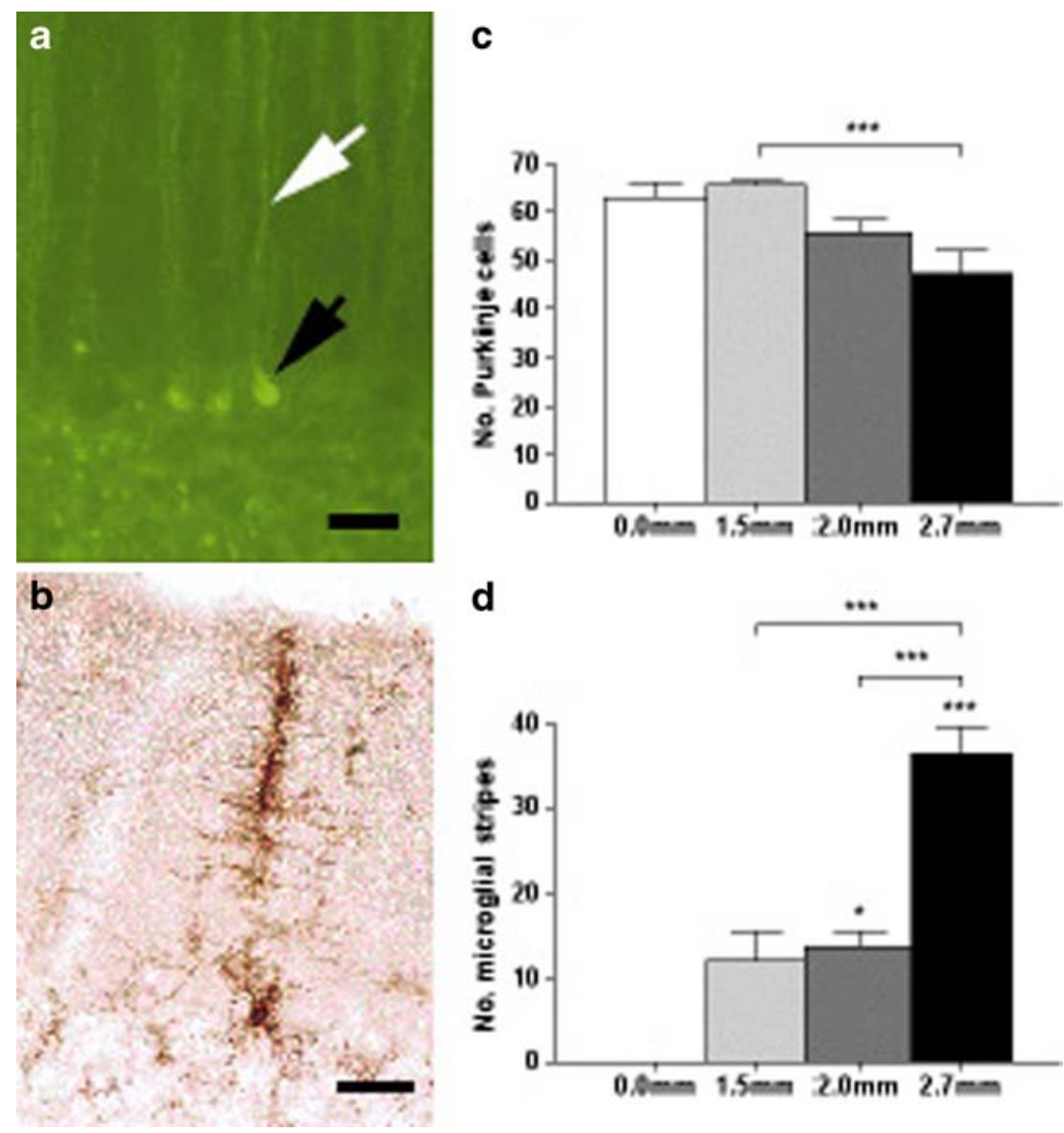
which the weight is dropped modulates the severity of injury. The resulting injury is characterized by diffuse edema and axonal injury that includes the cerebellar peduncles but no focal supratentorial lesion [42]. In this model of injury, Tuzgen et al. [44] reported reduced expression of nitric oxide metabolites within the cerebellum just 5 min post-injury, suggesting a relationship to decreased blood flow seen immediately after TBI.

This model has been paired with induction of post-injury hypoxia $(\mathrm{WDIA}+\mathrm{H})$ to generate a model of TBI that may more closely mimic clinical TBI. When compared with the lateral FPI model in terms of neurodegeneration and behavioral outcomes, Hallam et al. [31] found a slightly delayed time course of cerebellar Purkinje cell injury. FPI results in marked Fluoro-Jade immunostaining of Purkinje cells and their dendrites within the molecular layer within $24 \mathrm{~h}$ post-injury. In contrast, after WDIA $+\mathrm{H}$, there are only a few degenerating Purkinje cells and dendrites at $24 \mathrm{~h}$, but these numbers dramatically increased by 48 h. By 7 days post-injury, only degenerating dendrites remain.

Rotational Acceleration Injury This newly developed model mimics a rotational force against the brain and is characterized by diffuse subarachnoid hemorrhage, cortical hemorrhages, and astrogliosis [45]. The head is fixed within a frame that rotates about the head's sagittal center of mass. A piston then strikes the frame causing the animal's head to rotate into extension [45]. In this model of head injury, brain edema and an excitotoxic neuronal microenvironment result in extensive delayed neuronal cell death by apoptotic necrosis in various brain regions including the cerebellum [46]. TdT-Mediated dUTP nick-end labeling (TUNEL)positive cells are noted in the cerebellum beginning $24 \mathrm{~h}$ post-injury and peaking 3 days later [46]. The inducible transcription factor, c-Jun, expressed during apoptosis, is observed within the cerebellum in the nuclei of granule cells and cytoplasm of Purkinje and Golgi cells, astrocytes, and microglia [46]. Although there is co-localization of TUNEL staining and c-Jun in a subset of granule cells, indicative of apoptosis, c-Jun is also localized within the perikarya of TUNEL-negative cells, supporting a link between c-Jun expression and regenerating cells.

The rotational acceleration injury model has also been used to study the effects of TBI on elements of the neuronal cytoskeleton. Hamberger et al. [47] reported loss of the heavy phosphorylated subunit of neurofilament in axons within the cerebellar molecular layer by 3 days postinjury, indicating axonal injury. Of note, this finding is associated with abnormal accumulation of this neurofilament subunit within the perikarya of neurons in the olivary nucleus, further suggesting a link between damage to the cerebellum and injury within the olivary nucleus.

\section{Models of Direct Cerebellar Trauma}

Although direct trauma to the cerebellum does not have a strong clinical relevance, it does provide a basis for understanding the underlying events that contribute to cerebellar vulnerability. These models of direct trauma are typically adaptations of those used to produce injuries to the cerebral cortex, as discussed in the preceding paragraphs.

Ai and Baker [48, 49] applied a FPI over the posterior fossa in order to study the electrophysiology of a direct cerebellar insult. This resulted in presynaptic hyperexcitability within mossy fiber granule cell synapses at 3 days post-injury followed by hyperexcitability within granule cell-Purkinje cell synapses 3-7 days post-injury. These findings may account for the vulnerability of Purkinje cells to TBI. They further demonstrated that direct cerebellar injury alters the presynaptic potential in parallel fibers and suggest that this mechanism could be responsible for selective Purkinje cell death in TBI via a group II metabotropic glutamate receptor-dependent mechanism [49].

Allen and Chase [50] adapted the weight drop injury model to generate direct injury to the left cerebellar hemisphere. They used this model to investigate expression of heat shock proteins within cerebellar cell types. Mild injury induced hsp-27 protein expression in Purkinje cells and Bergmann glia, while severe injury also induced hsp-27 protein expression in neurons of the deep cerebellar nuclei. This study also examined sensorimotor function using the beam walk test and found that while mild injury led to no detectable deficits, severely injured animals showed significant deficits by 2 days post-injury. These deficits did not fully recover even by 20 days post-injury, suggesting a profound effect of focal cerebellar injury on motor behavior and cellular indicators of neuronal damage and repair.

\section{Models that Characterize Specific Components of TBI}

As with human TBI, the injury generated by experimental models such as CCI and FPI is complex, involving multiple regions of the brain and resulting in diverse types of neuronal injury. Several models of TBI have aimed to simplify the findings from CCI and FPI by focusing on specific aspects of TBI.

Axotomy One of the earliest methods of investigating the response of neurons to injury was axotomy, whereby the cerebellar peduncles are unilaterally severed [51]. Because of the unique properties of Purkinje cells, this model has become a valuable tool in the study of neuronal repair and plasticity [52]. Variations of this injury target the specific white matter tracts to provide directed axonal injury either to climbing fibers from the olivary nucleus within the 
inferior cerebellar peduncle [53] or Purkinje cell fibers [54]. Such studies have revealed a stark contrast in the response to axotomy between Purkinje cells and climbing fiber input [55]. Climbing fibers show a strong response to axonal injury characterized by axonal regression, but they have a remarkable ability to regenerate if provided a suitable environment. On the contrary, Purkinje cells are relatively resistant to such injury but seem to lack the ability to regenerate regardless of environmental conditions [52, 55]. These findings contradict the vulnerability of Purkinje cells to the previously discussed models of TBI, suggesting either that Purkinje cell axonal injury may not be a strong component of TBI or that other injury mechanisms overshadow this resistance to axonal damage.

Stab Injury Stab injury is another simple model that has been used to study direct trauma to the cerebral cortex and cerebellum. This method uses a sharp instrument to penetrate the surface of the brain. Culic et al. [56] used this model to study the electrocortical response of the cerebellum to forebrain injury. They demonstrated decreases in the mean power and desynchronization of various cerebellar electrocortical signals within minutes after injury and lasting up to $4 \mathrm{~h}$ post-injury, further demonstrating the vulnerability of the cerebellum to indirect injury. Chen and Aston-Jones [57] studied direct cerebellar injury by stabbing the lateral cerebellum with either a glass micropipette or a razor blade to study nitric oxide synthase activity using the marker NADPH diaphorase. They reported staining of this marker within the cell bodies, dendrites, and proximal axons of Purkinje cells adjacent to the injury area. These cells lost dendrites and shrank in size over 6 weeks following injury, suggesting degeneration in the Purkinje cells residing closest to the injury site. NADPH diapohrase positivity in neurons within the inferior olivary nucleus was also noted. Similar to the degenerating Purkinje cells, these cells also demonstrated dendritic loss and cell body shrinkage.

In Vitro Stretch Injury To further study the mechanical aspects of TBI, Ellis et al. [58] developed an in vitro model of stretch injury. Cells are grown in culture on a silastic membrane. The membrane is then distorted by a pulse of nitrogen to stretch the overlying cells. The extent of stretch injury can be modified by altering the amplitude and duration of the pressure pulse. This model has been used to characterize the response of neurons and glia from various regions to stretch injury. Slemmer et al. [59] cultured cerebellar cells (both neurons and glia together) in this model. This insult produced cell membrane disruption, release of injury markers, cell loss of both Purkinje cells and non-Purkinje neurons, and reactive astrogliosis by Bergmann glia. In addition, they measured increased levels of S-100 $\beta$ in injured co-cultures. To test the effect of this molecule on uninjured cells, they added it to control cultures and found a significant reduction in Purkinje cell numbers. While not yet used to study cerebellar injury, several other methods of in vitro traumatic injury exist, including axotomy, compression, barotrauma, acceleration/ deceleration, and hydrodynamic injury [60].

Excitotoxicity There are several models of excitotoxic damage to the cerebellum, including both genetic mutations and toxins [61]. One of the most relevant to the study of cerebellar trauma is the psychoactive drug ibogaine. Ibogaine is an analog of melatonin and has been shown to reduce the addictive potential of drugs such as cocaine and morphine in animal models [62]. In animals, it also causes tremor and results in loss of Purkinje cells and activation of Bergmann astrocytes and microglia $[62,63]$. Similar to CCI and FPI, degenerating Purkinje cells are found within the cerebellar vermis aligned in parasagittal stripes [64]. O'Hearn and Molliver [65] demonstrated that such cerebellar damage is mediated via excitement of the inferior olivary nucleus. Chemical ablation of this nucleus protects the Purkinje cells from ibogaine-induced damage. These findings suggest that sustained excitation of the olivocerebellar projections leads to the distinct pattern of Purkinje cell loss seen in models of TBI.

\section{Transmission of Injury to the Cerebellum}

The human studies and animal models discussed here suggest that traumatic injury, either directly to the cerebellum or indirectly following trauma to a distant part of the brain, leads to pathophysiologic findings in the cerebellum. The indirect damage can be transmitted by several methods, such as mechanical forces, metabolic changes, and presynaptic hyperexcitability.

Mechanical Forces Mechanical forces, such as contrecoup injury, are likely due to the impact of the brain on the skull caused by deceleration and inertial forces. Some of the effects of TBI, such as Purkinje cell death and cytoskeletal derangement, could be mediated by these mechanical forces. Purkinje cells are especially susceptible to mechanical forces [66]. Cytoskeletal derangements include significant axonal shearing, loss of cytoskeletal proteins (NF68, NF200, and microtubule-associated protein 2), focal neurofilament compaction, and alteration in axolemmal permeability $[67,68]$. These cytoskeletal derangements may not be exclusively restricted to sites of contusion and cell death $[69,70]$. In addition, preferential dendritic cytoskeletal derangements may be an early morphological feature of experimental TBI in vivo. 
Metabolic Changes Metabolic changes, such as crossed cerebellar diaschisis (CCD), and ischemic conditions can contribute to the transmission of injury effects to the cerebellum [17]. These involve depressed metabolic activity in the contralateral cerebellar hemisphere associated with ipsilateral metabolic changes following the initial trauma [19]. In a model of stroke, CCD is shown to be a result of functional deafference as well as transneuronal degeneration [71].

Presynaptic hyperexcitability Presynaptic hyperexcitability at cerebellar synapses has been reported at 3-7 days following FPI. This involves an increase in neurotransmission in the cerebellar pathways from mossy fibers to granule cells (mossy fibers) and from granule cells to Purkinje cells (parallel fibers) [48]. This leads to loss of neurons in the cerebellum [48]. Purkinje cells may also be particularly vulnerable to climbing fiber hyperexcitability because of the large number of synaptic connections between them. The olivary nucleus, from which climbing fiber connections originate, has been implicated in rotational acceleration injury, stab injury, and excitotoxic injury models [47, 57, 65] and could explain the vulnerability of the vermis to trauma.

These different methods of indirect injury transmission contribute in varying degrees to the manifestations of cerebellar vulnerability in different models of traumatic brain injury and are summarized in Fig. 4.

\section{Mechanisms Underlying Cerebellar Injury}

Following either direct or indirect cerebellar injury, several pathophysiologic mechanisms mediating TBI-induced cerebellar damage can be identified. These include Purkinje cell loss due to excitotoxic injury, activation of an

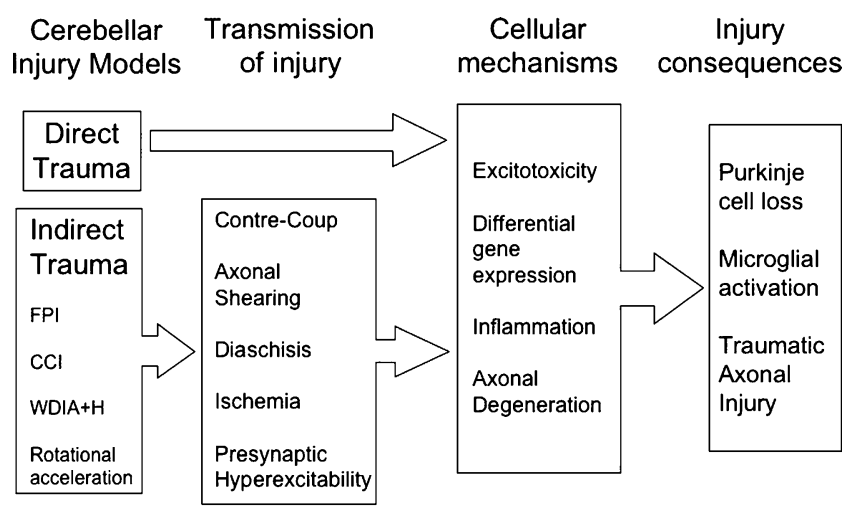

Fig. 4. The pathophysiology of traumatic cerebellar injury is complex, involving multiple mechanisms of cellular injury as well as multiple modes of transmission in the case of indirect cerebellar injury. FPI fluid percussion injury, $C C I$ controlled cortical impact, $W D I A+H$ weight drop impact acceleration + hypoxia inflammatory response, and traumatic axonal injury [48, $50,57]$. The various factors contributing to the consequences of traumatic injury to the cerebellum in the experimental models described in this review are summarized in Fig. 4.

Excitotoxic Injury Purkinje cell loss is evident in all models of injury to the cerebellum and exhibits a specific spatial pattern as described earlier. While the mechanisms involved are not well understood, several studies suggest that this loss is due to excitotoxic injury to the neurons $[61,72]$. Purkinje cells receive input from two sources, both of which are excitatory-climbing fibers from neurons within the inferior olivary nucleus of the medulla and parallel fibers from granule cells within the cerebellum [72]. Each Purkinje cell receives input from only a single climbing fiber, but has an estimated 1,500 synaptic connections with that climbing fiber. Nearly 100,000 parallel fibers synapse with a single Purkinje cell. This anatomical connectivity of the cerebellum, as well as the specialized neuronal-glial interactions between Purkinje cells and Bergman glia [73], could explain the unique spatial pattern of susceptibility of the Purkinje neurons to TBI.

Another factor underlying the specific spatial patterning of Purkinje cell injury is differential gene expression. Purkinje cell expresses multiple glutamate receptors, but it is thought that $\alpha$-amino-3-hydroxy-5-methyl-4-isoxazolepropionic acid (AMPA) receptors play the largest role in glutamate-mediated excitotoxic damage to Purkinje cells in many disease processes [61]. Slemmer et al. [74] found that Purkinje neurons lacking aldolase $\mathrm{C}$ expression were more susceptible both in the CCI model of injury and AMPAmediated excitotoxicity. Aldolase $\mathrm{C}$ is a glycolytic enzyme which has been shown to co-localize with excitatory amino acid transporter 4 in Purkinje cells, conferring two possible methods of neuroprotection in this subgroup of cells [75]. In the cortex, downregulation of glial glutamate transporter proteins following CCI has been shown. This may lead to defective glutamate uptake and a chronic low-level increase in glutamate concentrations, suggesting that regulation of glutamate-mediated excitotoxicity plays a role in secondary neuronal damage after TBI [76]. Similarly, alteration in the normal function of metabotropic glutamate receptors and the glutamate reuptake system in the cerebellum following FPI could underlie the hyperexcitability in the cerebellum [49], consistent with the hypothesis that excitotoxic mechanisms are involved in traumatic Purkinje cell death.

Inflammatory Response Strong microglial activation is a common inflammatory response observed following injury to the cerebellum. Following either FPI or CCI, activated microglia are organized perpendicular to the Purkinje cell layer [28, 32]. Importantly, this activation precedes evi- 
dence of neuronal loss. Activated microglia may be sensitive indicators of Purkinje cell injury and serve as cellular scavengers to remove debris and promote wound healing [77]. Thus, neuroprotective mechanisms may play a role in the selective vulnerability displayed by the Purkinje neuron population [30]. Alternatively, activated microglia may be involved in promoting Purkinje cell death [28, 78]. An endothelin receptor antagonist transiently attenuates microglial reactivity when administered for the first $24 \mathrm{~h}$ post-injury, but does not effect Purkinje cell death [36], suggesting that microglial activation is possibly a response to Purkinje cell death. The relationship between microglial activation and Purkinje cell death in the context of trauma needs to be further elucidated.

Traumatic Axonal Injury Injury to cerebellar white matter is another mechanism by which the functional consequences of TBI can be mediated. Several animal models of brain trauma have reported traumatic axonal injury (TAI) in the cerebellum $[34,79]$. Current literature supports the idea that TAI is an evolving process, progressing from focal axonal damage at the time of injury to eventual complete disconnection [80]. Extensive bilateral axonal degeneration is observed in the cerebellum as a result of the biomechanical forces during CCI injury [34, 79, 81]. TBI-induced functional and structural deficits in cerebellar white matter have also been characterized. In FPI, early neurofilament degradation and persistent calpain-mediated degradation of $\propto$ II-spectrin is observed [82]. In a rotational acceleration head injury model, a redistribution of neurofilaments from axons to neuronal perikarya occurs in several brain regions including the cerebellum [47]. This is associated with the appearance of beta-amyloid positive neurons, findings that have been demonstrated after human TBI as well as in neurodegenerative diseases [83]. Cerebellar white matter function after TBI can be further assessed using compound action potential recordings. There is a significant decline in electrophysiological function in the posterior and middle cerebellum, which persists at 14 days post-injury, indicating persistent cerebellar white matter dysfunction [82]. Although structural axonal degeneration following trauma is well established, the varying elecrophysiologic susceptibilities of myelinated and demyelinated axon populations in the cerebellum remain to be further investigated.

\section{Conclusion}

Cerebellar injury has been shown to be an important component of human TBI. While still a relatively poorly studied phenomenon, the models discussed in this review have begun to elucidate the nature of cerebellar damage following both direct and indirect injury. In the case of indirect injury to the cerebellum, different methods of transmission of injury to the cerebellum have been identified, including mechanical forces, metabolic changes, and presynaptic hyperexcitability. Several pathophysiologic mechanisms mediating TBI-induced cerebellar damage have also been described following direct or indirect injury: excitotoxicity leading to Purkinje cell loss, an evolving TAI, and a distinct spatial pattern of microglial activation coincident with Purkinje cell loss. Importantly, many of these features of injury have been noted across multiple injury models, suggesting common underlying mechanisms of cerebellar vulnerability that may lead to many of the behavioral sequelae of TBI. The models discussed in this review are necessary tools to further explore these processes.

Acknowledgment This work was supported by NIH/NINDS NS050159.

Open Access This article is distributed under the terms of the Creative Commons Attribution Noncommercial License which permits any noncommercial use, distribution, and reproduction in any medium, provided the original author(s) and source are credited.

\section{References}

1. Hyder AA, Wunderlich CA, Puvanachandra P, Gururaj G, Kobusingye OC (2007) The impact of traumatic brain injuries: a global perspective. NeuroRehabilitation 22(5):341-353

2. Thurman DJ, Alverson C, Dunn KA, Guerrero J, Sniezek JE (1999) Traumatic brain injury in the United States: a public health perspective. J Head Trauma Rehabil 14(6):602-615

3. Braga LW, Souza LN, Najjar YJ, Dellatolas G (2007) Magnetic resonance imaging (MRI) findings and neuropsychological sequelae in children after severe traumatic brain injury: the role of cerebellar lesion. J Child Neurol 22(9):1084-1089

4. Basford JR, Chou LS, Kaufman KR, Brey RH, Walker A, Malec JF et al (2003) An assessment of gait and balance deficits after traumatic brain injury. Arch Phys Med Rehabil 84(3):343-349

5. Kuhtz-Buschbeck JP, Hoppe B, Golge M, Dreesmann M, Damm-Stunitz U, Ritz A (2003) Sensorimotor recovery in children after traumatic brain injury: analyses of gait, gross motor, and fine motor skills. Dev Med Child Neurol 45(12):821-828

6. Louis ED, Lynch T, Ford B, Greene P, Bressman SB, Fahn S (1996) Delayed-onset cerebellar syndrome. Arch Neurol 53 (5):450-454

7. Mysiw WJ, Corrigan JD, Gribble MW (1990) The ataxic subgroup: a discrete outcome after traumatic brain injury. Brain Inj 4(3):247-255

8. Wober C, Oder W, Kollegger H, Prayer L, Baumgartner C, Wober-Bingol C et al (1993) Posturographic measurement of body sway in survivors of severe closed head injury. Arch Phys Med Rehabil 74(11):1151-1156

9. Tsai FY, Teal JS, Itabashi HH, Huprich JE, Hieshima GB, Segall HD (1980) Computed tomography of posterior fossa trauma. J Comput Assist Tomogr 4(3):291-305

10. Spanos GK, Wilde EA, Bigler ED, Cleavinger HB, Fearing MA, Levin HS et al (2007) Cerebellar atrophy after moderate-to-severe pediatric traumatic brain injury. AJNR Am J Neuroradiol 28 (3):537-542 
11. Soto-Ares G, Vinchon M, Delmaire C, Abecidan E, Dhellemes P, Pruvo JP (2001) Cerebellar atrophy after severe traumatic head injury in children. Childs Nerv Syst 17(4-5):263-269

12. van Gijn J (2007) Symptomatology of cerebellar tumours; a study of forty cases. by T. Grainger (Registrar) and Gordon Holmes (Resident Medical Office, National Hospital, Queen Square, London). Brain 1904; 27:522-591. with The symptoms of acute cerebellar injuries due to gunshot injuries. by Gordon Holmes. Brain 1917; 40:461-535. with The cerebellum of man. by Gordon Holmes. Brain 1939; 62:1-30. Brain 130(1):4-7

13. Bramanti P, Sessa E, Saltuari L (1994) Post-traumatic mutism. J Neurosurg Sci 38(2):117-122

14. Iwadate Y, Saeki N, Namba H, Odaki M, Oka N, Yamaura A (1989) Post-traumatic intention tremor-clinical features and CT findings. Neurosurg Rev 12(Suppl 1):500-507

15. Sato M, Chang E, Igarashi T, Noble LJ (2001) Neuronal injury and loss after traumatic brain injury: time course and regional variability. Brain Res 917(1):45-54

16. Gale SD, Baxter L, Roundy N, Johnson SC (2005) Traumatic brain injury and grey matter concentration: a preliminary voxel based morphometry study. J Neurol Neurosurg Psychiatry 76 (7):984-988

17. Alavi A, Mirot A, Newberg A, Alves W, Gosfield T, Berlin J et al (1997) Fluorine-18-FDG evaluation of crossed cerebellar diaschisis in head injury. J Nucl Med 38(11):1717-1720

18. Newberg AB, Alavi A, Alavi J (2000) Contralateral cortical diaschisis in a patient with cerebellar astrocytoma after radiation therapy. Clin Nucl Med 25(6):431-433

19. Niimura K, Chugani DC, Muzik O, Chugani HT (1999) Cerebellar reorganization following cortical injury in humans: effects of lesion size and age. Neurology 52(4):792-797

20. Lupi A, Bertagnoni G, Salgarello M, Orsolon P, Malfatti V, Zanco P (2007) Cerebellar vermis relative hypermetabolism: an almost constant PET finding in an injured brain. Clin Nucl Med 32 (6):445-451

21. Hattori N, Huang SC, Wu HM, Yeh E, Glenn TC, Vespa PM et al (2003) Correlation of regional metabolic rates of glucose with Glasgow coma scale after traumatic brain injury. J Nucl Med 44 (11):1709-1716

22. Fiez JA, Petersen SE, Cheney MK, Raichle ME (1992) Impaired non-motor learning and error detection associated with cerebellar damage. A single case study. Brain 115(Pt 1):155-178

23. Grafman J, Litvan I, Massaquoi S, Stewart M, Sirigu A, Hallett M (1992) Cognitive planning deficit in patients with cerebellar atrophy. Neurology 42(8):1493-1496

24. Middleton FA, Strick PL (1994) Anatomical evidence for cerebellar and basal ganglia involvement in higher cognitive function. Science 266(5184):458-461

25. Dayer A, Roulet E, Maeder P, Deonna T (1998) Post-traumatic mutism in children: clinical characteristics, pattern of recovery and clinicopathological correlations. Eur J Paediatr Neurol 2 (3):109-116

26. Matschke J, Laas R, Schulz F (2007) Cerebellar atrophy following mild head injury in a 4-year-old girl. Pediatr Neurosurg 43 (4):330-333

27. Thompson HJ, Lifshitz J, Marklund N, Grady MS, Graham DI, Hovda DA et al (2005) Lateral fluid percussion brain injury: a 15year review and evaluation. J Neurotrauma 22(1):42-75

28. Fukuda K, Aihara N, Sagar SM, Sharp FR, Pitts LH, Honkaniemi $\mathrm{J}$ et al (1996) Purkinje cell vulnerability to mild traumatic brain injury. J Neurotrauma 13(5):255-266

29. Fukuda K, Richmon JD, Sato M, Sharp FR, Panter SS, Noble LJ (1996) Induction of heme oxygenase-1 (HO-1) in glia after traumatic brain injury. Brain Res 736(1-2):68-75
30. Park E, McKnight S, Ai J, Baker AJ (2006) Purkinje cell vulnerability to mild and severe forebrain head trauma. J Neuropathol Exp Neurol 65(3):226-234

31. Hallam TM, Floyd CL, Folkerts MM, Lee LL, Gong QZ, Lyeth BG et al (2004) Comparison of behavioral deficits and acute neuronal degeneration in rat lateral fluid percussion and weightdrop brain injury models. J Neurotrauma 21(5):521-539

32. Mautes AE, Fukuda K, Noble LJ (1996) Cellular response in the cerebellum after midline traumatic brain injury in the rat. Neurosci Lett 214(2-3):95-98

33. Ding Y, Yao B, Lai Q, McAllister JP (2001) Impaired motor learning and diffuse axonal damage in motor and visual systems of the rat following traumatic brain injury. Neurol Res 23(2-3):193-202

34. Hoshino S, Kobayashi S, Furukawa T, Asakura T, Teramoto A (2003) Multiple immunostaining methods to detect traumatic axonal injury in the rat fluid-percussion brain injury model. Neurol Med Chir (Tokyo) 43(4):165-173 discussion 74

35. Macrae IM, Robinson MJ, Graham DI, Reid JL, McCulloch J (1993) Endothelin-1-induced reductions in cerebral blood flow: dose dependency, time course, and neuropathological consequences. J Cereb Blood Flow Metab 13(2):276-284

36. Sato M, Noble LJ (1998) Involvement of the endothelin receptor subtype A in neuronal pathogenesis after traumatic brain injury. Brain Res 809(1):39-49

37. Cernak I (2005) Animal models of head trauma. NeuroRx 2 (3): $410-422$

38. Lighthall JW, Dixon CE, Anderson TE (1989) Experimental models of brain injury. J Neurotrauma 6(2):83-97

39. Lighthall JW (1988) Controlled cortical impact: a new experimental brain injury model. J Neurotrauma 5(1):1-15

40. Igarashi T, Potts MB, Noble-Haeusslein LJ (2007) Injury severity determines Purkinje cell loss and microglial activation in the cerebellum after cortical contusion injury. Exp Neurol 203(1):258-268

41. Tong W, Igarashi T, Ferriero DM, Noble LJ (2002) Traumatic brain injury in the immature mouse brain: characterization of regional vulnerability. Exp Neurol 176(1):105-116

42. Foda MA, Marmarou A (1994) A new model of diffuse brain injury in rats. Part II: morphological characterization. J Neurosurg 80(2):301-313

43. Marmarou A, Foda MA, van den Brink W, Campbell J, Kita H, Demetriadou K (1994) A new model of diffuse brain injury in rats. Part I: pathophysiology and biomechanics. J Neurosurg 80 (2):291-300

44. Tuzgen S, Tanriover N, Uzan M, Tureci E, Tanriverdi $\mathrm{T}$, Gumustas $\mathrm{K}$ et al (2003) Nitric oxide levels in rat cortex, hippocampus, cerebellum, and brainstem after impact acceleration head injury. Neurol Res 25(1):31-34

45. Gutierrez E, Huang Y, Haglid K, Bao F, Hansson HA, Hamberger A et al (2001) A new model for diffuse brain injury by rotational acceleration: I model, gross appearance, and astrocytosis. J Neurotrauma 18(3):247-257

46. Runnerstam M, Bao F, Huang Y, Shi J, Gutierrez E, Hamberger A et al (2001) A new model for diffuse brain injury by rotational acceleration: II. Effects on extracellular glutamate, intracranial pressure, and neuronal apoptosis. J Neurotrauma 18(3):259-273

47. Hamberger A, Huang YL, Zhu H, Bao F, Ding M, Blennow K et al (2003) Redistribution of neurofilaments and accumulation of beta-amyloid protein after brain injury by rotational acceleration of the head. J Neurotrauma 20(2):169-178

48. Ai J, Baker A (2002) Presynaptic hyperexcitability at cerebellar synapses in traumatic injury rat. Neurosci Lett 332(3):155-158

49. Ai J, Baker A (2004) Presynaptic excitability as a potential target for the treatment of the traumatic cerebellum. Pharmacology 71 (4):192-198 
50. Allen GV, Chase T (2001) Induction of heat shock proteins and motor function deficits after focal cerebellar injury. Neuroscience 102(3):603-614

51. Bower AJ, Waddington G (1981) A simple operative technique for chronically severing the cerebellar peduncles in neonatal rats. $\mathrm{J}$ Neurosci Methods 4(2):181-188

52. Rossi F, Gianola S, Corvetti L (2006) The strange case of Purkinje axon regeneration and plasticity. Cerebellum 5(2):174-182

53. Sherrard RM (1997) Insulin-like growth factor 1 induces climbing fibre re-innervation of the rat cerebellum. Neuroreport 8(15):32253228

54. Dusart I, Sotelo C (1994) Lack of Purkinje cell loss in adult rat cerebellum following protracted axotomy: degenerative changes and regenerative attempts of the severed axons. J Comp Neurol 347(2):211-232

55. Carulli D, Buffo A, Strata P (2004) Reparative mechanisms in the cerebellar cortex. Prog Neurobiol 72(6):373-398

56. Culic M, Blanusa LM, Grbic G, Spasic S, Jankovic B, Kalauzi A (2005) Spectral analysis of cerebellar activity after acute brain injury in anesthetized rats. Acta Neurobiol Exp (Wars) 65(1):11-17

57. Chen S, Aston-Jones G (1994) Cerebellar injury induces NADPH diaphorase in Purkinje and inferior olivary neurons in the rat. Exp Neurol 126(2):270-276

58. Ellis EF, McKinney JS, Willoughby KA, Liang S, Povlishock JT (1995) A new model for rapid stretch-induced injury of cells in culture: characterization of the model using astrocytes. J Neurotrauma 12(3):325-339

59. Slemmer JE, Weber JT, De Zeeuw CI (2004) Cell death, glial protein alterations and elevated S-100 beta release in cerebellar cell cultures following mechanically induced trauma. Neurobiol Dis $15(3): 563-572$

60. Kumaria A, Tolias CM (2008) In vitro models of neurotrauma. $\mathrm{Br}$ J Neurosurg 22(2):200-206

61. Sarna JR, Hawkes R (2003) Patterned Purkinje cell death in the cerebellum. Prog Neurobiol 70(6):473-507

62. Xu Z, Chang LW, Slikker W Jr, Ali SF, Rountree RL, Scallet AC (2000) A dose-response study of ibogaine-induced neuropathology in the rat cerebellum. Toxicol Sci 57(1):95-101

63. O'Hearn E, Long DB, Molliver ME (1993) Ibogaine induces glial activation in parasagittal zones of the cerebellum. Neuroreport 4 (3):299-302

64. O'Hearn E, Molliver ME (1993) Degeneration of Purkinje cells in parasagittal zones of the cerebellar vermis after treatment with ibogaine or harmaline. Neuroscience 55(2):303-310

65. O'Hearn E, Molliver ME (1997) The olivocerebellar projection mediates ibogaine-induced degeneration of Purkinje cells: a model of indirect, trans-synaptic excitotoxicity. J Neurosci 17(22):8828-8841

66. Shaw NA (2002) The neurophysiology of concussion. Prog Neurobiol 67(4):281-344

67. Povlishock JT, Marmarou A, McIntosh T, Trojanowski JQ, Moroi J (1997) Impact acceleration injury in the rat: evidence for focal axolemmal change and related neurofilament sidearm alteration. $J$ Neuropathol Exp Neurol 56(4):347-359
68. Taft WC, Yang K, Dixon CE, Hayes RL (1992) Microtubuleassociated protein 2 levels decrease in hippocampus following traumatic brain injury. J Neurotrauma 9(3):281-290

69. Posmantur RM, Kampfl A, Liu SJ, Heck K, Taft WC, Clifton GL et al (1996) Cytoskeletal derangements of cortical neuronal processes three hours after traumatic brain injury in rats: an immunofluorescence study. J Neuropathol Exp Neurol 55(1):68-80

70. Posmantur RM, Kampfl A, Taft WC, Bhattacharjee M, Dixon CE, Bao J et al (1996) Diminished microtubule-associated protein 2 (MAP2) immunoreactivity following cortical impact brain injury. J Neurotrauma 13(3):125-137

71. Liu Y, Karonen JO, Nuutinen J, Vanninen E, Kuikka JT, Vanninen RL (2007) Crossed cerebellar diaschisis in acute ischemic stroke: a study with serial SPECT and MRI. J Cereb Blood Flow Metab 27(10):1724-1732

72. Slemmer JE, De Zeeuw CI, Weber JT (2005) Don't get too excited: mechanisms of glutamate-mediated Purkinje cell death. Prog Brain Res 148:367-390

73. Park E, Ai J, Baker AJ (2007) Cerebellar injury: clinical relevance and potential in traumatic brain injury research. Prog Brain Res 161:327-338

74. Slemmer JE, Haasdijk ED, Engel DC, Plesnila N, Weber JT (2007) Aldolase C-positive cerebellar Purkinje cells are resistant to delayed death after cerebral trauma and AMPA-mediated excitotoxicity. Eur J Neurosci 26(3):649-656

75. Welsh JP, Yuen G, Placantonakis DG, Vu TQ, Haiss F, O’Hearn E et al (2002) Why do Purkinje cells die so easily after global brain ischemia? Aldolase C, EAAT4, and the cerebellar contribution to posthypoxic myoclonus. Adv Neurol 89:331-359

76. Rao VL, Baskaya MK, Dogan A, Rothstein JD, Dempsey RJ (1998) Traumatic brain injury down-regulates glial glutamate transporter (GLT-1 and GLAST) proteins in rat brain. J Neurochem 70(5):2020-2027

77. Kim SU, de Vellis J (2005) Microglia in health and disease. J Neurosci Res 81(3):302-313

78. Marin-Teva JL, Dusart I, Colin C, Gervais A, van Rooijen N, Mallat M (2004) Microglia promote the death of developing Purkinje cells. Neuron 41(4):535-547

79. Lighthall JW, Goshgarian HG, Pinderski CR (1990) Characterization of axonal injury produced by controlled cortical impact. J Neurotrauma 7(2):65-76

80. Buki A, Povlishock JT (2006) All roads lead to disconnection?Traumatic axonal injury revisited. Acta Neurochir (Wien) 148 (2):181-193; discussion 93-94

81. Matthews MA, Carey ME, Soblosky JS, Davidson JF, Tabor SL (1998) Focal brain injury and its effects on cerebral mantle, neurons, and fiber tracks. Brain Res 794(1):1-18

82. Park E, Liu E, Shek M, Park A, Baker AJ (2007) Heavy neurofilament accumulation and alpha-spectrin degradation accompany cerebellar white matter functional deficits following forebrain fluid percussion injury. Exp Neurol 204(1):49-57

83. Graham DI, Gennarelli T (1997) Trauma. In: Graham DI, Lantos PL (eds) Greenfield's neuropathology. Arnold, London, pp 197-262 